\title{
The rabbit meat : characterization of carcasses produced in France
}

\author{
A. DELAVEAU \\ I.T.A.V.I., Service technique, \\ 28, we du Rocher, 75008 Paris (France)
}

During a study on the quality of rabbit meat, we tried to determine the characteristics of the rabbit carcass. For this purpose, we realised a number of measurements on carcasses in I 4 French slaughterhouses.

Multidimensional analyses allowed us to determine three characteristic measures :

- the pelvis length,

- the back length,

- the pelvis circumference

We noticed noreover that it was easy to characterize the carcasses of meat rabbits according to the origin of the animals (traditional or rational productions).

Thus, it was possible to distinguish between three types of carcasses. The first one composed of long and lean rabbit carcasses coming from traditionnal production systems, the second one composed of shorter and fatter carcasses coming from rational production systems, the third one being an intermediary type.

\section{During the suckling period \\ should the does have free access to the nest or should they be limited to 15 minutes per day?}

\author{
L. CORDIER \\ Centrale Coopérative de productions animales \\ I2, ne des Beaux Soleils, 95520 Osny (France)
}

A total of 65 New Zealand doe rabbits was divided into 2 groups. The doe rabbits of the control group had free access to their nest box while those of the experimental group were limited to 15 minutes per day (at about 7.30 a.m.) till the young rabbits were I 7 days old.

The litter size, the young rabbit mortality and the mean weight at weaning were not significantly different from one group to the other.

However, the result was in favour of the experimental group because the decrease in the litter abandon rate allowed to gain $\mathrm{I} .5$ young rabbit per year and per mother cage. 